\title{
Prehypertension and psychosocial risk factors among university students in ASEAN countries
}

\author{
Karl Peltzer ${ }^{1,2^{*}}$ (D), Supa Pengpid ${ }^{3,4}$, Vanphanom Sychareun ${ }^{5}$, Alice Joan G. Ferrer ${ }^{6}$, Wah Yun Low ${ }^{7}$, \\ Thang Nguyen Huu ${ }^{8}$, Hla Hla Win ${ }^{9}$, Erna Rochmawati ${ }^{10}$ and Niruwan Turnbull ${ }^{11}$
}

\begin{abstract}
Background: Existing evidence suggests that the cardiovascular morbidities are increasing among pre-hypertensive individuals compared to normal. The aim of this study was to evaluate the prevalence of prehypertension, hypertension and to identify psychosocial risk factors for prehypertension among university students in Association of South East Asian Nation (ASEAN) countries.

Methods: Based on a cross-sectional survey, the total sample included 4649 undergraduate university students (females $=65.3 \%$; mean age 20.5, SD = 2.9, age range of 18-30 years) from 7 ASEAN countries (Indonesia, Laos, Malaysia, Myanmar, Philippines, Thailand and Vietnam). Blood pressure, anthropometric, health behaviour and psychosocial variables were measured.

Results: Overall, $19.0 \%$ of the undergraduate university students across ASEAN countries had prehypertension, 6.7\% hypertension and $74.2 \%$ were normotensives. There was country variation in prehypertension prevalence, ranging from $11.3 \%$ in Indonesia and $11.5 \%$ in Malaysia to above 18\% in Laos, Myanmar and Thailand. In multivariate analysis, sociodemographic variables (male gender, living in an upper middle income country, and living on campus or off campus on their own), nutrition and weight variables (not being underweight and obese, having once or more times soft drinks in a day and never or rarely having chocolate or candy), heavy drinking and having depressive symptoms were associated with prehypertension.
\end{abstract}

Conclusion: The study found a high prevalence of prehypertension in ASEAN university students. Several psychosocial risk factors including male gender, obesity, soft drinks consumption, heavy drinking and depression symptoms have been identified which can help in intervention programmes.

\section{Background}

Several studies have shown an increase in the prevalence of hypertension in high and low and middle income countries $[1,2]$. Similar to the trend worldwide, "hypertension is also the single most attributable cause for mortality in South-East Asia. But while in developed regions, the prevalence of hypertension appears to be stabilizing or decreasing, the rates in Southeast Asia continue to rise" [3]. If you are prehypertensive, you are more likely to become hypertensive and have a higher cardiovascular risk

\footnotetext{
* Correspondence: karl.peltzer@tdt.edu.vn

'Department for Management of Science and Technology Development, Ton Duc Thang University, Ho Chi Minh City, Vietnam

${ }^{2}$ Faculty of Pharmacy, Ton Duc Thang University, Ho Chi Minh City, Vietnam Full list of author information is available at the end of the article
}

(compared with normotensives), and comprehensive therapeutic lifestyle modification strategy in prehypertensive subjects is indicated to reduce the risk of developing hypertension [4, 5]. In addition, studies found that hypertension and prehypertension can start in adolescence (or earlier) and continue into adulthood [6]. A study among young adults (20-30 years) found that students were at higher risk for prehypertension than the general youth population [7].

Currently, there are few studies on the assessment of prehypertension in young adults or university students in Association of Southeast Asian Nations (ASEAN). For example, in Malaysia the prevalence of prehypertension among university students was found to be $30.1 \%$ [8] to 42.9\% [9], in the Philippines 13.9\% [10] and in Thailand 
44.5\% [11]. Among Indian medical students a prehypertension prevalence rate of $45 \%$ [12] and in another study among male undergraduate students in India 55.1\% [13] was found. Studies among university students in the Middle East found a prehypertension prevalence of 47.4\% in Egypt [14], 39.5\% in Kuwait [15], and 13.5\% among females in Saudi Arabia [16].

Psychosocial risk factors associated with prehypertension or hypertension among university students and general adult population may include sociodemographics such as male gender $[15,17]$, nutrition variables such as Body Mass Index (BMI) overweight/obesity [7, 12, 15, $16,18,19]$, excess sodium intake $[7,20]$, inadequate intake of fruit and vegetables [13, 20], and health risk behaviour variables such as physical inactivity [20, 21], substance use, including smoking $[15,22]$, heavy alcohol use $[23,24]$ and short sleep duration [23, 25, 26]. Psychosocial stress and support may include depression [8, 27, 28], posttraumatic stress disorder (PTSD) [29], low life satisfaction [30], and lack of social support [25, 31, 32].

As a result, the purpose of this study was to evaluate the prevalence of prehypertension, hypertension and to identify psychosocial risk factors for prehypertension based on a cross-sectional survey of a university undergraduate population in ASEAN countries (Indonesia, Laos, Malaysia, Myanmar, Philippines, Thailand and Vietnam).

\section{Methods}

\section{Study design and participants}

This cross-sectional study was part of a larger investigation of a range of health behaviours in university students, and was conducted by a network of researchers in participating countries (see Acknowledgments). The university selection was a convenient sample.

\section{Procedure}

The questionnaire utilised for data collection was developed in English, then translated and back-translated into the languages (Bahasa, Khmer, Lao, Myanmar, Thai, Vietnamese) of the participating countries. Research assistants administered the questionnaire at the end of a teaching class (inclusion criteria: all students present in class). In each study country, undergraduate students were surveyed in classrooms selected through as stratified random sample procedure (one university department randomly selected from each faculty as a primary sampling unit, and for each selected department randomly ordered undergraduate courses). Participation rates were in all countries more than 90\%, except for Indonesia $86 \%$ and Myanmar $73 \%$.

\section{Measures}

\section{Blood pressure (BP) measurements and classification}

Three consecutive measurements of systolic and diastolic BP were measured by well-trained research assistants using appropriately sized cuff and the bell of a standard stethoscope, with at least 1 min between assessments after the participant had rested for $5 \mathrm{~min}$ in a sitting position. Average blood pressure was calculated arithmetically for the 3 measurements of each systolic and diastolic blood pressure. Missing values were excluded from being ncluded in the study. Blood pressure classification was done using JNC 7 algorithm [33]. Prehypertension was defined as systolic blood pressure (SBP) measurement of $120-139 \mathrm{mmHg}$ or diastolic blood pressure (DBP) of 80 $89 \mathrm{mmHg}$ in people who were not taking antihypertensive medication. Hypertension was defined as SBP $\geq 140 \mathrm{mmHg}$ and/or DBP $\geq 90 \mathrm{mmHg}$ and/or current use of antihypertensive medication. Normotension was defined as BP values $<120 / 80 \mathrm{mmHg}$ in students who were not taking antihypertensive medication [34]. All respondents were initially asked if they have ever been diagnosed with hypertension and if they did, whether or not they have been taking any kind of drugs or other treatment for the last 2 weeks and last 12 months.

Socio-demographic factor questions included age, gender, residential status, subjective socioeconomic background, and country income status [35].

\section{Nutrition variables}

Anthropometric measurements. Height (without footwear) using a stadiometer and weight (without footwear and any heavy accessories) using a calibrated weighing scale was measured. Body mass index (BMI) was calculated as weight in $\mathrm{kg}$ divided by height in metre squared. Body mass index (BMI) was classified according to Asian criteria: normal weight $(18.5$ to $<23.0)$, overweight $(23.0$ to $<25.0)$ and $25+$ as obese [36].

Fruit and vegetable (FV) consumption was assessed with two questions, "How many servings of fruit do you eat on a typical day?" and "How many servings of vegetables do you eat on a typical day?" (One standard serving = $80 \mathrm{~g}$ ) [37]. Cronbach alpha for this fruit and vegetable measure was 0.74 . Insufficient fruit and vegetable consumption was defined as less than five servings of fruits and/or vegetables a day [37]. Cronbach alpha for the two questions in this sample was FV 0.68.

Additional dietary variables included: (a) trying to avoid eating foods that contain fat and cholesterol (yes, no); (b) adding salt to meals ( $1=$ usually to $4=$ never); (c) eat a meal that includes meat (beef, pork, lamb, etc.) ( $1=$ at least once a day to $5=$ never); [38], (d) times per day usually drink carbonated soft drinks in the past 30 days $(1=$ None to $7=5$ or more times per day, (e) Number of days ate food from a fast food restaurant in the past 7 days $(1=0$ days to $8=7$ days) [39], and (f) frequency of consuming chocolate or candy $(1=$ more than once a day to $6=$ never). 


\section{Health behaviour}

Physical activity. Physical activity was assessed using the self-administered International Physical Activity Questionnaire (IPAQ) short version, for the last 7 days (IPAQ-S7S). We used the instructions given in the IPAQ manual [40], and categorized physical activity (short form) according to the official IPAQ scoring protocol [41] as low, moderate and high.

Tobacco use was assessed with the question: Do you currently use one or more of the following tobacco products (cigarettes, snuff, chewing tobacco, cigars, etc.)? Response options were "yes" or "no" [42].

Past month binge drinking was assessed with one item of the Alcohol Use Disorder Identification Test [43].

Sleep duration. The survey also included one question about self-reported hours of sleep, on average in a $24 \mathrm{~h}$ period. The category of 7-8 h of sleep was used as reference. This reference category was chosen because some studies reported that those who slept 7 or $8 \mathrm{~h}$ usually had the lowest mortality risk [44].

\section{Psychosocial stress measures}

Post traumatic stress disorder (PTSD). Breslau's 7-item screener was used to identify PTSD symptoms in the past month; participants who scored four or more were considered to have a positive screen for PTSD [45]. (Cronbach alpha $=0.77)$.

The Centres for Epidemiologic Studies Depression Scale (CES-D: 10 items) was used to assess depressive symptoms, and scores 15 or more were classified as severe depressive symptoms [46] (Cronbach's alpha $=0.71$ ).

\section{Well-being and social support}

Life satisfaction was assessed with one item, "All things considered, how satisfied are you with your life as a whole?" Response option ranged from 1 = very satisfied to 5 = very dissatisfied [38].

Social support was measured with three items from the Social Support Questionnaire [47]. (Cronbach's alpha 0.64).

\section{Data analysis}

The data were analyzed using IBM-SPSS for Windows, version 23 (Chicago, Illinois, USA). Descriptive statistics were used to calculate frequency of study variables of the study population and Chi-square test to assess difference in proportions. Logistic regression analyses were used to test significant determinants of prehypertension status, with prehypertension serving as the dichotomous outcome variable (prehypertension versus normotensives) and sociodemographics, health, nutrition and psychosocial stress as the independent predictor variables.

\section{Results}

\section{Sample characteristics}

The total sample included 4649 undergraduate university students (females $=65.3 \%$; mean age 20.5, $\mathrm{SD}=2.9$, age range of 18-30 years) from 7 ASEAN countries (Indonesia, Laos, Malaysia, Myanmar, Philippines, Thailand and Vietnam). Among countries, the sample size ranged from 231 in Indonesia to 1019 in Malaysia. Overall, $19.0 \%$ of the undergraduate university students across ASEAN countries had prehypertension, 6.7\% hypertension and $74.2 \%$ were normotensives. Of those who were classified as having hypertension, $29.8 \%$ were currently using of antihypertensive medication. There was country variation in prehypertension prevalence, ranging from $11.3 \%$ in Indonesia and $11.5 \%$ in Malaysia to above $18 \%$ in Laos, Myanmar and Thailand. The hypertension prevalence ranged from 3 to $4 \%$ in Laos, Malaysia and Philippines to above $12 \%$ in Indonesia and Thailand. Overall, prehypertension and hypertension prevalence was higher among male than female university students (see Tables 1 and 2).

\section{Association between psychosocial risk factors and prehypertension}

In bivariate analyses, sociodemographic variables (male gender, living in an upper middle income country, and living on campus or off campus on their own), nutrition and weight variables (not being underweight and obese, not usually adding salt in food, having once or more times soft drinks in a day and never or rarely having chocolate or candy), health behaviour variables (high physical activity, current tobacco use and heavy drinking), having depressive symptoms, low life satisfaction and low social support were associated with prehypertension.

In multivariate analysis, sociodemographic variables (male gender, living in an upper middle income country, and living on campus or off campus on their own), nutrition and weight variables (not being underweight and obese, having once or more times soft drinks in a day and never or rarely having chocolate or candy), heavy drinking and having depressive symptoms were associated with prehypertension (see Table 3 ).

\section{Discussion}

The study found among a large sample of undergraduate university students across seven ASEAN countries a prehypertension prevalence of $19.0 \%$, which seems generally lower than previous in the region $[8,9,11-13]$ and in the middle east $[14,15]$. There was some country variation in prehypertension prevalence, ranging from $11.3 \%$ in Indonesia and $11.5 \%$ in Malaysia to above $18 \%$ in Laos, Myanmar and Thailand. Students residing in upper middle income countries such as Thailand had a higher prevalence of prehypertension than those in lower middle income countries. These country differences in terms of prehypertension 
Table 1 Sample characteristics $(N=4649)$

\begin{tabular}{|c|c|c|c|c|}
\hline Sociodemographics & Normotensives & Prehypertension & Hypertension & $P$-value \\
\hline$\overline{A l l}$ & $3451(74.2)$ & $885(19.0)$ & $313(6.7)$ & \\
\hline \multicolumn{5}{|l|}{ Age in years } \\
\hline $18-19$ & $1193(74.1)$ & $200(11.7)$ & $117(7.3)$ & \multirow[t]{3}{*}{0.448} \\
\hline $20-21$ & $1294(74.1)$ & $330(18.9)$ & $123(7.0)$ & \\
\hline $22-30$ & $964(74.6)$ & $255(19.7)$ & $73(6.7)$ & \\
\hline \multicolumn{5}{|l|}{ Gender } \\
\hline Female & $2453(80.8)$ & $422(13.9)$ & $161(5.3)$ & \multirow[t]{2}{*}{$<0.001$} \\
\hline Male & $997(61.8)$ & $463(28.7)$ & $152(9.4)$ & \\
\hline \multicolumn{5}{|l|}{ Economic family background } \\
\hline Wealthy & $1055(74.4)$ & $256(18.1)$ & $107(7.5)$ & \multirow[t]{2}{*}{0.218} \\
\hline Poor & $2396(74.2)$ & $629(19.5)$ & $206(6.4)$ & \\
\hline \multicolumn{5}{|l|}{ Country income } \\
\hline Upper middle income & $1189(65.4)$ & $446(24.5)$ & $184(10.1)$ & \multirow[t]{2}{*}{$<0.001$} \\
\hline Lower middle income & $2262(79.9)$ & $439(15,5)$ & $129(4.6)$ & \\
\hline \multicolumn{5}{|l|}{ Country } \\
\hline Indonesia $(N=231)$ & $177(76.6)$ & $16(11.3)$ & $28(12.1)$ & \multirow[t]{7}{*}{$<0.001$} \\
\hline $\operatorname{Laos}(N=717)$ & $550(76.7)$ & $139(19.4)$ & $28(3.9)$ & \\
\hline Malaysia $(N=1019)$ & $751(73.7)$ & $36(11.5)$ & $10(3.2)$ & \\
\hline Myanmar $(N=314)$ & $268(85.4)$ & $190(18.6)$ & $78(7.7)$ & \\
\hline Philippines $(N=775)$ & $638(82.3)$ & $112(14.5)$ & $25(3.2)$ & \\
\hline Thailand $(N=800)$ & $438(54.8)$ & $256(32.8)$ & $106(13.3)$ & \\
\hline Vietnam ( $N=793)$ & $629(79.3)$ & $126(15.9)$ & $38(4.8)$ & \\
\hline \multicolumn{5}{|l|}{ Living arrangement } \\
\hline Lives with parents/guardians & $1017(79.3)$ & $206(16.1)$ & $53(4.6)$ & \multirow[t]{2}{*}{$<0.001$} \\
\hline Live away from parents & $2431(72.3)$ & $679(20.2)$ & $254(7.6)$ & \\
\hline
\end{tabular}

prevalence may be attributed to different stages of the epidemiologic transition of the participating student populations in the various countries. As found in some previous studies $[15,17]$, this study found a significant higher prevalence of prehypertension among male (28.7\%) than female (13.9\%) students. Nevertheless, a large proportion of, especially male, university students in ASEAN countries seem to suffer from prehypertension requiring comprehens ive lifestyle modification programmes [4].

Compared with students who were residing with their parents or guardians, students who were living on campus or off campus on their own were at a higher risk for prehypertension. It is possible that students living away from their parents are more influenced by their peers in terms of lifestyle changes increasing the development of prehypertension. Regarding weight variables, being underweight was protective and being obese increased the odds of having prehypertension. The association between overweight/ obesity and prehypertension and hypertension has been confirmed in a number of studies [7, 12, 15, 16, 18, 19]. Further, having once or more times soft drinks in a day increased the odds of prehypertension and moderate consumption of chocolate or candy (1-6 times a week) was protective of prehypertension. In a systematic review, Ried et al. [48] found that "flavanol-rich chocolate and cocoa products may have a small but statistically significant effect in lowering blood pressure by $2-3 \mathrm{~mm} \mathrm{Hg}$ in the short term." Unlike a few previous studies [7, 13, 20], this study did not find an association between excess sodium intake, inadequate intake of fruit and vegetables and prehypertension. A previous study [49], found an association between sodium intake and hypertension in the older age group but not in the younger age group, so it is possible that other risk factors (such as obesity) for raised blood pressure play a larger role than sodium intake at the age of young adulthood [50]. Another study among Chinese adults also did not find an association between salt intake and prhypertension [51]. Another possible reason for this result could be recall bias resulting from self-reporting of salt intake [51].

Regarding health risk behaviours, this study found that heavy drinking students had an higher odds of having 
Table 2 Sample characteristics $(N=4649)$

\begin{tabular}{|c|c|c|c|c|}
\hline Nutrition variables & Normotensives & Prehypertension & Hypertension & $P$-value \\
\hline \multicolumn{5}{|l|}{ Body Mass Index (BMI) } \\
\hline Normal & $1922(75.6)$ & $470(18.5)$ & $152(6.0)$ & \multirow[t]{4}{*}{$<0.001$} \\
\hline Underweight & $810(81.1)$ & $126(12.6)$ & $62(6.2)$ & \\
\hline Overweight & $330(71.3)$ & $101(21.8)$ & $32(6.9)$ & \\
\hline Obese & $307(56.5)$ & $171(31.5)$ & $65(12.0)$ & \\
\hline Usually eat salt & $1175(77.4)$ & $252(16.6)$ & $91(6.0)$ & 0.002 \\
\hline Avoid foods containing fat and cholesterol & $1241(73.5)$ & $316(18.7)$ & $11(7.8)$ & 0.102 \\
\hline Insufficient fruits and vegetables & $2636(75.2)$ & $651(18.6)$ & $220(6.3)$ & 0.046 \\
\hline Soft drinks (once or more a week) ${ }^{1}$ & $682(67.7)$ & $232(23.0)$ & $94(9.3)$ & 0.003 \\
\hline Fast food (once or more a week) ${ }^{1}$ & $1240(73.2)$ & $338(20.0)$ & $115(6.8)$ & 0.006 \\
\hline Red meat at least once a day & $1980(75.0)$ & $503(19.0)$ & $158(6.0)$ & 0.065 \\
\hline \multicolumn{5}{|l|}{ Chocolate or candy ${ }^{a}$} \\
\hline Never or rarely & $926(67.3)$ & $311(22.6)$ & $139(10.1)$ & \multirow[t]{3}{*}{$<0.001$} \\
\hline 1-6 times a week & $973(75.0)$ & $238(18.3)$ & $87(6.7)$ & \\
\hline Once or more times a day & $364(75.4)$ & $85(17.6)$ & $34(7.0)$ & \\
\hline \multicolumn{5}{|l|}{ Health behaviour } \\
\hline \multicolumn{5}{|l|}{ Physical activity } \\
\hline Low & $1974(75.1)$ & $473(18.0)$ & $182(6.9)$ & \multirow[t]{3}{*}{0.069} \\
\hline Moderate & $1462(73.3)$ & $409(20.5)$ & $124(6.2)$ & \\
\hline High & $469(69.8)$ & $160(23.8)$ & $43(6.4)$ & \\
\hline Current tobacco use & $114(65.9)$ & $47(27.2)$ & $12(6.9)$ & 0.018 \\
\hline Heavy drinking at least monthly & $199(63.4)$ & $95(30.3)$ & $20(6.4)$ & $<0.001$ \\
\hline \multicolumn{5}{|l|}{ Sleep duration } \\
\hline $7-8 \mathrm{~h}$ & $1572(75.5)$ & $370(17.8)$ & $140(6.7)$ & \multirow[t]{3}{*}{0.385} \\
\hline 6 or less hours & $1574(73.2)$ & $429(20.0)$ & $147(6.8)$ & \\
\hline 9 or more hours & $294(75.6)$ & $73(18.8)$ & $22(5.7)$ & \\
\hline \multicolumn{5}{|l|}{ Psychosocial stress } \\
\hline Depression (severe) & $308(64.3)$ & $114(23.8)$ & $57(11.9)$ & $<0.001$ \\
\hline Posttraumatic stress disorder (PTSD) & $812(72.4)$ & $230(20.5)$ & $79(7.0)$ & 0.312 \\
\hline \multicolumn{5}{|l|}{ Well-being and social support } \\
\hline \multicolumn{5}{|l|}{ Life satisfaction } \\
\hline Low & $1918(71.9)$ & $545(20.4)$ & $204(7.6)$ & \multirow[t]{3}{*}{$<0.001$} \\
\hline Medium & $456(71.3)$ & $102(20.4)$ & $41(8.2)$ & \\
\hline High & $1174(79.4)$ & $237(16.0)$ & $68(4.6)$ & \\
\hline \multicolumn{5}{|l|}{ Social support } \\
\hline Low & $1565(71.6)$ & $450(20.6)$ & $172(7.9)$ & \multirow[t]{2}{*}{$<0.001$} \\
\hline High & $1875(76.6)$ & $433(17.7)$ & $141(5.8)$ & \\
\hline
\end{tabular}

${ }^{a}$ Not assessed in Laos and Philippines

prehypertension, as also found in previous studies $[23,24]$. Although current evidence suggests that the moderate consumption of alcohol lowers the blood pressure, chronic ethanol consumption ( $\geq$ three drinks a day) is associated with an increased incidence of hypertension [52]. Tobacco use was found in bivariate analysis associated with prehypertension prevalence, as also some previous studies found a significant association [15, 22]. Unlike several previous studies [20-23, 25, 26], this study did not find an association between physical inactivity, short sleep duration and prehypertension. However, several other studies also did not find a clear association between physical inactivity and raised blood pressure $[53,54]$. It is possible that the driving force behind increased blood pressure in this 
Table 3 Pedictors of pre-hypertension compared to normal blood pressure

\begin{tabular}{|c|c|c|}
\hline Sociodemographics & UOR $(95 \% \mathrm{Cl})$ & $\operatorname{AOR}(95 \% \mathrm{Cl})^{\mathrm{a}}$ \\
\hline \multicolumn{3}{|l|}{ Age in years } \\
\hline $18-19$ & 1 (Reference) & \multirow[t]{3}{*}{-} \\
\hline $20-21$ & $1.01(0.85-1.21)$ & \\
\hline $22-30$ & $1.05(0.87-1.27)$ & \\
\hline \multicolumn{3}{|l|}{ Gender } \\
\hline Female & 1 (Reference) & 1 (Reference) \\
\hline Male & $2.70(2.32-3.14)^{* * *}$ & $2.56(2.17-3.02)^{* * *}$ \\
\hline \multicolumn{3}{|l|}{ Economic family background } \\
\hline Wealthy & 1 (Reference) & \multirow[t]{2}{*}{-} \\
\hline Poor & $0.92(0.79-1.09)$ & \\
\hline \multicolumn{3}{|l|}{ Country income } \\
\hline Upper middle income & 1 (Reference) & 1 (Reference) \\
\hline Lower middle income & $0.52(0.45-0.60)^{* * *}$ & $0.52(0.42-0.64)^{* * *}$ \\
\hline \multicolumn{3}{|l|}{ Living arrangement } \\
\hline Lives with parents/guardians & 1 (Reference) & 1 (Reference) \\
\hline Lives away from parents/guardians & $1.38(1.16-1.64)^{* * *}$ & $1.39(1.03-1.89)^{*}$ \\
\hline \multicolumn{3}{|l|}{ Nutrition variables } \\
\hline \multicolumn{3}{|l|}{ Body Mass Index (BMI) } \\
\hline Normal & 1 (Reference) & 1 (Reference) \\
\hline Underweight & $0.64(0.51-0.79)^{* * *}$ & $0.67(0.52-0.87)^{* *}$ \\
\hline Overweight & $1.25(0.98-1.60)$ & $1.11(0.86-1.43)$ \\
\hline Obese & $2.28(1.84-2.82)^{* * *}$ & $1.94(1.55-2.43)^{* * *}$ \\
\hline Usually eat salt & $0.77(0.65-0.91)^{* *}$ & $0.97(0.82-1.16)$ \\
\hline Avoid foods containing fat and cholesterol & $1.00(0.86-1.17)$ & - \\
\hline Insufficient fruits and vegetables & $0.88(0.73-1.07)$ & - \\
\hline Soft drinks (once or more a week) ${ }^{1}$ & $1.34(1.11-1.61)^{* *}$ & $1.56(1.27-1.92)^{* * *}$ \\
\hline Fast food (once or more a week) ${ }^{1}$ & $0.95(0.79-1.13)$ & - \\
\hline Red meat at least once a day & $1.00(0.86-1.16)$ & - \\
\hline \multicolumn{3}{|l|}{ Chocolate or candy $^{1}$} \\
\hline Never or rarely & 1 (Reference) & 1 (Reference) \\
\hline 1-6 times a week & $0.73(0.60-0.88)^{* *}$ & $0.74(0.60-0.90)^{* *}$ \\
\hline Once or more times a day & $0.70(0.53-0.91)^{* *}$ & $0.82(0.62-1.09)$ \\
\hline \multicolumn{3}{|l|}{ Health behaviour } \\
\hline \multicolumn{3}{|l|}{ Physical activity } \\
\hline Low & 1 (Reference) & 1 (Reference) \\
\hline Moderate & $1.05(0.88-1.24)$ & $0.89(0.74-1.07)$ \\
\hline High & $1.36(1.08-1.71)^{* *}$ & $1.25(0.98-1.59)$ \\
\hline Current tobacco use & $1.65(1.16-1.64)^{* *}$ & $1.03(0.70-1.51)$ \\
\hline Heavy drinking at least monthly & $1.96(1.32-2.54)^{* * *}$ & $1.91(1.43-2.54)^{* * *}$ \\
\hline \multicolumn{3}{|l|}{ Sleep duration } \\
\hline $7-8 h$ & 1 (Reference) & \multirow[t]{3}{*}{-} \\
\hline 6 or less hours & $0.86(0.74-1.01)$ & \\
\hline 9 or more hours & $0.91(0.69-1.20)$ & \\
\hline
\end{tabular}

Psychosocial stress and support 
Table 3 Pedictors of pre-hypertension compared to normal blood pressure (Continued)

\begin{tabular}{llr}
\hline Depression (severe) & $1.51(1.20-1.90)^{* * *}$ & $1.32(1.00-1.76)^{*}$ \\
Posttraumatic stress disorder (PTSD) & $1.14(0.96-1.35)$ & - \\
Life satisfaction & & 1 (Reference) \\
Low & 1 (Reference) & $1.01(0.78-1.31)$ \\
Medium & $1.01(0.79-1.28)$ & $0.97(0.78-1.21)$ \\
High & $0.71(0.60-0.84)^{* * *}$ & 1 (Reference) \\
Social support & & $0.90(0.77-1.05)$ \\
Low & 1 (Reference) \\
High & $0.80(0.69-0.93)^{* *}$ & 1.90 \\
\hline
\end{tabular}

${ }^{a}$ Hosmer \& Lemeshow Chi-square $=15.14, P=0.057$; Nagelkerke $R^{2}: 0.12 ;{ }^{* * *} P<.001 ;{ }^{* *} P<.01 ;{ }^{*} P<.05$

UOR Unadjusted Odds Ratio; AOR Adjusted Odds Ratio; Cl Confidence Interval; ${ }^{1}$ not assessed in Laos and Philippines

study population is not solely physical inactivity but is linked to other factors such as obesity, which still can be advocated for in order to improve a healthy body [53]. Further, in a previous review [55], it was found that the association between short sleep and higher blood pressure and hypertension was stronger among middle aged adults, which could possibly mean that among a younger age (emerging adulthood) effects of short sleep on raised blood pressure are not yet found.

In terms of psychosocial stress and support, this study found in agreement with previous studies $[8,27,28]$ that depression was positively related to prehypertension. "There is considerable evidence suggesting that hyperreactivity of the sympathetic nervous system and genetic influences are the underlying mechanisms in the relationship between depression and hypertension." [56] Further, in bivariate analysis this study found and association between low life satisfaction, and lack of social support and prehypertension, as found in previous studies [25, 30-32].

\section{Study limitations}

First, the sample was representative of the population from which it was drawn as all participants were participants of undergraduate students of one university. However, for the same reason, the sample might not be representative of universities. Apart from anthropometric and blood pressure measurements, a limitation of the study was that all the other information collected in the study was based on self reporting. It is possible that certain behaviours were under reported. Further, it was a cross-sectional study and the temporal or antecedent consequent relationships between risk factors and the development of prehypertension cannot be established in such studies. Longitudinal study of this cohort will enable analysis of the impact of such behaviour in early life on subsequent development of health problems.

\section{Conclusion}

The study found high prevalence, in particular among men, of prehypertension in a large sample of university students across seven ASEAN countries. Often, in university students, prehypertension may not be discovered until late. This is because university students are generally healthy and will normally not go for a routine health check-up. The data from this study draws attention to the importance of examining the blood pressure of young persons. Several psychosocial risk factors including male gender, obesity, soft drinks consumption, heavy drinking and depression symptoms have been identified which can help in intervention programmes.

\section{Abbreviations}

ASEAN: Association of Southeast Asian Nations; BMl: Body Mass Index; FV: Fruit and vegetable; IPAQ: International Physical Activity Questionnaire (IPAO); PTSD: Posttraumatic Stress Disorder

\section{Acknowledgments}

The following colleagues participated in this ASEAN student health survey and contributed to data collection (locations of universities in parentheses): Indonesia: Erna Rochmawati (Yogyakarta), Laos: Vanphanom Sychareun (Vientiane); Malaysia: Wah Yun Low (Kuala Lumpur); Myanmar: Hla Hla Win (Yangon); Philippines: Alice Ferrer (Miagao); Thailand: Niruwan Turnbull (Maha Sarakham); Vietnam: Thang Nguyen Huu (Hanoi).

\section{Funding}

Partial funding for this study was provided by the South African Department of Higher Education.

\section{Availability of data and materials}

The data for the current study will not be shared publicly as participants were informed at the time of providing consent that only researchers involved in the project would have access to the information they provided.

\section{Authors' contributions}

All authors fulfill the criteria for authorship. KP and SP conceived and designed the research. VS, AJGF, WYL, TNH, HHW, ER and NT acquired the data. KP and SP performed statistical analysis. KP, SP, VS, AJGF drafted the manuscript and made critical revision of the manuscript for key intellectual content. All authors read and approved the final version of the manuscript. All authors have agreed to authorship and order of authorship for this manuscript. 


\section{Ethics approval and consent to participate}

The study was conducted in accordance with the Declaration of Helsinki and was approved by an ethical committee in each participating country. "Research Ethics Committee, Faculty of Medicine and Health Sciences", Universitas Muhammadiyah Yogyakarta; the University of Malaya Medical Ethics committee (MECID 201412-905), Malaysia; "Research and Ethical Committee of University of Medicine 1", Yangon, Myanmar; "Office of the Committee for Research Ethics (Social Sciences), the Faculty of Social Sciences and Humanities", Mahidol University, Thailand (MU-SSIRB 2015/ 116(B2); "Ethics Committee at University of Health Sciences", Laos Ethics; "Committee of the Western Visayas Health Research", Philippines; and "Committee of Research Ethics of Hanoi School of Public Health", Vietnam. Informed consent was obtained from each participant, and privacy and confidentially of the respondents were strictly protected.

\section{Consent for publication}

Not applicable.

\section{Competing interests}

The authors declare that they have no competing interests.

\section{Publisher's Note}

Springer Nature remains neutral with regard to jurisdictional claims in published maps and institutional affiliations.

\section{Author details \\ 'Department for Management of Science and Technology Development, Ton Duc Thang University, Ho Chi Minh City, Vietnam. ${ }^{2}$ Faculty of Pharmacy, Ton Duc Thang University, Ho Chi Minh City, Vietnam. ${ }^{3}$ ASEAN Institute for Health Development, Mahidol University, Salaya, Thailand. ${ }^{4}$ Department of Research \& Innovation, University of Limpopo, Polokwane, South Africa. ${ }^{5}$ Faculty of Postgraduate Studies, University of Health Sciences, Ministry of Health Vientiane, Vientiane, Lao PDR. ${ }^{6}$ Division of Social Sciences, University of the Philippines Visayas, Miagao, 5023 Iloilo, Philippines. ${ }^{7}$ Faculty of Medicine, University of Malaya, Kuala Lumpur, Malaysia. ${ }^{8}$ Faculty of Public Health, Hanoi Medical University, Hanoi, Vietnam. ${ }^{9}$ Preventive and Social Medicine Department, University of Medicine 1, Yangon, Myanmar. ${ }^{10}$ School of Nursing, Universitas Muhammadiyah Yogyakarta, Jl. Lingkar Selatan, Tamantirto, Kasihan, Bantul, DI Yogyakarta, Yogyakarta, Indonesia. ${ }^{11}$ Faculty of Public Health, Mahasarakham University, Maha Sarakham, Thailand.}

Received: 5 May 2017 Accepted: 16 August 2017

Published online: 23 August 2017

\section{References}

1. Egan BM, Zhao Y, Axon RN. US trends in prevalence, awareness, treatment, and control of hypertension, 1988-2008. JAMA. 2010;303:2043-50.

2. Ibrahim MM, Damasceno A. Hypertension in developing countries. Lancet. 2012;380(9841):611-9.

3. Castillo R. Prevalence and management of hypertension in Southeast Asia. J Hypertens. 2016;34 Suppl 1:e4. doi:10.1097/01.hjh.0000499881.98439.59.

4. Habib GB, Virani SS, Jneid H. Is 2015 the primetime year for prehypertension? Prehypertension: a cardiovascular risk factor or simply a riskmarker? J Am Heart Assoc. 2015;4(2):e001792. doi:10.1161/JAHA.115.001792.

5. Huang Y, Cai X, Liu C, Zhu D, Hua J, Hu Y, Peng J, Xu D. Prehypertension and the risk of coronary heart disease in Asian and Western populations: a metaanalysis. J Am Heart Assoc. 2015;4(2):e001519. doi:10.1161/JAHA.114.001519.

6. Redwine KM, Daniels SR. Prehypertension in adolescents: risk and progression. J Clin Hypertens 2012. 14(6):360-4. doi:10.1111/j.1751-7176. 2012.00663.x.

7. Kini S, Kamath VG, Kulkarni MM, Kamath A, Shivalli S. Pre-hypertension among young adults (20-30 years) in coastal villages of Udupi District in southern India: an alarming scenario. PLoS One. 2016;11(4):e0154538. doi:10.1371/journal.pone.0154538. eCollection 2016.

8. Balami AD, Salmiah MS, Nor Afiah MZ. Psychological determinants of prehypertension among first year undergraduate students in a public University in Malaysia. Malaysian J Pub Health Med. 2014;14(2):67-76.

9. Lee PY, Ong TA, Muna S, Syed Alwi SAR, Kamarudin K. Do university students have high cardiovascular risk? A pilot study from Universiti Malaysia Sarawak (UNIMAS). Malaysian Family Physician. 2010;5(1):41-3.
10. Pengpid S, Peltzer K, Ferrer AJ. Prehypertension and associated factors among university students in the Philippines. Int J Adolesc Med Health. 2014;26(2):245-52.

11. Sirilak S. Prevalence of hypertension and prehypertension in university students: association with overweight and obesity. Buddhachinaraj Med J. 2013;30(2):15-22.

12. Debbarma A, Bhattacharjya H, Mohanty A, Mog C. Prevalence of prehypertension and its relationship with body mass index among the medical students of Agartala government medical college. Int J Res Med Sci. 2015; 3(5):1097-101. doi:10.5455/2320-6012.ijrms20150513.

13. Logaraj M, Madhavan RSD, Balaji R. Prevalence of pre hypertension and its association to risk factors for cardiovascular diseases among male undergraduate students in Chennai. Int J Com Med Public Health. 2016;3(2):542-51.

14. Soliman M, El-Salamony O, El-Khashab K, El-Sherbiny NA, Khamis S. Study of hypertension among Fayoum university students. Int J Public Health Res. 2014;2(2):15-9.

15. Al-Majed HT, Sadek AA. Pre-hypertension and hypertension in college students in Kuwait: a neglected issue. J Family Community Med. 2012;19(2): 105-12.

16. Koura MR, Al-Dabal BK, Rasheed P, Al-Sowielem LS, Makki SM. Prehypertension among young adult females in Dammam, Saudi Arabia. East Mediterr Health J. 2012;18(7):728-34.

17. Nkeh-Chungag BN, Mxhosa TH, Mgoduka PN. Association of waist and hip circumferences with the presence of hypertension and pre-hypertension in young South African adults. Afr Health Sci. 2015;15(3):908-16. doi:10.4314/ahs.v15i3.27.

18. Chen YP, Li J, Liang XJ, Zhang J, Cai L, Huang SM, et al. Impact of body mass index on blood pressures in a college student population. Nan Fang Yi Ke Da Xue Xue Bao. 2011;31(1):100-2.

19. Ali M, Yusuf HI, Stahmer J, Rahlenbeck SI. Cardiovascular risk factors and physical activity among university students in Somaliland. J Community Health. 2015;40(2):326-30

20. Collier SR, Landram MJ. Treatment of prehypertension: lifestyle and/or medication. Vasc Health Risk Manag. 2012;8:613-9.

21. Zhang WH, Zhang L, An WF, Ma JL. Prehypertension and clustering of cardiovascular risk factors among adults in suburban Beijing China J Epidemiol. 2011;21(6):440-6.

22. Tayem Yl, Yaseen NA, Khader WT, Abu Rajab LO, Ramahi AB, Saleh MH. Prevalence and risk factors of obesity and hypertension among students at a central university in the West Bank. Libyan J Med. 2012;7. doi:10.3402/ljm. v7i0.19222.

23. Tadesse $\mathrm{T}$, Alemu $\mathrm{H}$. Hypertension and associated factors among university students in Gondar, Ethiopia: a cross-sectional study. BMC Public Health. 2014;14:937. doi:10.1186/1471-2458-14-937.

24. Jorgensen RS, Maisto SA. Alcohol consumption and prehypertension: an investigation of university youth. Behav Med. 2008;34(1):21-8.

25. Cuffee Y, Ogedegbe C, Williams NJ, Ogedegbe G, Schoenthaler A Psychosocial risk factors for hypertension: an update of the literature. Curr Hypertens Rep. 2014;16(10):483. doi:10.1007/s11906-014-0483-3.

26. Guo X, Zheng L, Li Y, Yu S, Liu S, Zhou X, et al. Association between sleep duration and hypertension among Chinese children and adolescents. Clin Cardiol. 2011;34(12):774-81.

27. Vaccarino V, Johnson BD, Sheps DS, Reis SE, Kelsey SF, Bittner V, et al. Depression, inflammation, and incident cardiovascular disease in women with suspected coronary ischemia: the National Heart, Lung, and Blood Institute-sponsored WISE study. J Am Coll Cardiol. 2007:50:2044-50.

28. Lee AK, Corneille MA, Hall NM, Yancu CN, Myers M. The stressors of being young and black: cardiovascular health and black young adults. Psychol Health. 2016;31(5):578-91.

29. Rosengren A, Hawken S, Ounpuu S, Sliwa K, Zubaid M, Almahmeed WA, et al. Association of psychosocial risk factors with risk of acute myocardial infarction in 11119 cases and 13648 controls from 52 countries (the INTERHEART study): case-control study. Lancet. 2004;364:953-62.

30. Romero Martinez V, Eglé S, Villasmil JJ. Relationship between life satisfaction levels and high blood pressure in adolescents: PP.14.43. J Hypertension. 2010; 28 - p e260. doi:10.1097/01.hjh.0000378969.24759.c5.

31. Carels RA, Blumenthal JA, Sherwood A. Effect of satisfaction with social support on blood pressure in normotensive and borderline hypertensive menand women. Int J Behav Med. 1998:5(1):76-85.

32. O'Donovan A, Hughes B. Social support and loneliness in college students: effects on pulse pressure reactivity to acute stress. Int J Adolesc Med Health. 2007;19(4):523-8. 
33. Chobanian AV, Bakris GL, Black HR, Cushman WC, Green LA, Izzo JL, et al. Seventh report of the joint National Committee of prevention, detection, evaluation, and treatment of high blood pressure. Hypertension. 2003;42: 1206-52.

34. Kim Y, Lee S. Prevalence and risk factors associated with prehypertension by gender and age in a Korean population in the KNHANES 2010-2012. Iran J Public Health. 2015;44(12):1594-1602.

35. World Bank. New Country Classifications. Available online. 2016; data. worldbank.org/news/new-country-classifications (accessed on 5 October 2016

36. Kanazawa M, Yoshiike N, Osaka T, Numba Y, Zimmet P, Inoue S. Criteria and classification of obesity in Japan and Asia-Oceania. World Rev Nutr Diet. 2005:94:1-12.

37. Hall JN, Moore S, Harper SB, Lynch JW. Global variability in fruit and vegetable consumption. Am J Prev Med. 2009;36(5):402-409.e5.

38. Wardle J, Steptoe A, Bellisle F, Davou B, Reschke K, Lappalainen R, et al. Healthy dietary practices among European students. Health Psychol. 1997; 16(5):443-50.

39. Centers for Disease Control (CDC). The Global School and Health Survey background. Available online: https://www.cdc.gov/gshs/. Accessed 18 May 2016.

40. Craig $C L$, Marshall AL, Sjöström M, Bauman AE, Booth ML, Ainsworth BE, et al. International physical activity questionnaire: 12-country reliability and validity. Med Sci Sports Exerc. 2003;35:1381-95.

41. International Physical Activity Questionnaire (IPAQ). IPAQ Scoring Protocol. Available online: https://sites.google.com/site/theipaq/. Accessed 5 Apr 2016.

42. World Health Organization (WHO). Guidelines for controlling and monitoring the tobacco epidemic. Geneva: WHO; 1998.

43. Babor TF, Higgins-Biddle JC, Saunders JB, Monteiro M. AUDIT: the alcohol use disorder identification test. Geneva: World Health Organization; 2001.

44. Hublin C, Partinen M, Koskenvuo M, Kaprio J. Sleep and mortality: a population-based 22 year follow-up study. Sleep. 2007;30:1245-53.

45. Kimerling R, Ouimette P, Prins A, Nisco P, Lawler C, Cronkite R, et al Brief report: utility of a short screening scale for DSM-IV PTSD in primary care. J Gen Intern Med. 2006;21(1):65-7.

46. Andresen EM, Malmgren JA, Carter WB, Patrick DL. Screening for depression in well older adults: evaluation of a short form of the CES-D (Center for Epidemiologic Studies Depression Scale). Am J Prev Med. 1994;10(2):77-84.

47. Brock D, Sarason I, Sarason B, Pierce G. Simultaneous assessment of perceived global and relationship specific support. J Soc Pers Relationships. 1996;13:143-52

48. Ried K, Sullivan TR, Fakler P, Frank OR, Stocks NP. Effect of cocoa on blood pressure. Cochrane Database Syst Rev. 2012;8:CD008893. doi:10.1002/14651858. CD008893.

49. Zhao $X$, Yang $X$, Zhang $X$, Li $Y$, Zhao $X$, Ren L, et al. Dietary salt intake and coronary atherosclerosis in patients with prehypertension. J Clin Hypertens. 2014;16(8):575-80. doi:10.1111/jch.12362. Epub 2014 Jun 23.

50. Haghighatdoost F, Sarrafzadegan N, Khosravi A, Noori F, Boshtam M, Mohammadifard N, Abdollhi Z, Azadbakht L. Is the association between salt intake and blood pressure mediated by body mass index and central adiposity? Arch Iran Med. 2013;16(3):167-71. doi:013163/AIM.009.

51. Xu T, Liu J, Zhu G, Liu J, Han S. Prevalence of prehypertension and associated risk factors among Chinese adults from a large-scale multi-ethnic population survey. BMC Public Health. 2016;16(1):775. doi:10.1186/s12889-016-3411-4.

52. Husain K, Ansari RA, Ferder L. Alcohol-induced hypertension: mechanism and prevention. World J Cardiol. 2014;6(5):245-52.

53. Afrifa-Anane E, Agyemang C, Codjoe SN, Ogedegbe G. de-graft Aikins A. The association of physical activity, body mass index and the blood pressure levels among urban poor youth in Accra, Ghana. BMC Public Health. 2015;15:269. doi:10.1186/s12889-015-1546-3.

54. Mkhonto SS, Labadarios D, Mabaso MLH. Association of bodyweight and physical activity with blood pressure in a rural population in the Dikgale village of Limpopo Province in South Africa. BMC Res Notes. 2012;5:118.

55. Gangwisch JE. A review of evidence for the link between sleep duration and hypertension. Am J Hypertens. 2014;27(10):1235-42. doi:10.1093/ajh/hpu071.

56. Scalco AZ, Scalco MZ, Azul JBS, Lotufo NF. Hypertension and depression. Clinics. 2005:60(3):241-50.

\section{Submit your next manuscript to BioMed Central and we will help you at every step:}

- We accept pre-submission inquiries

- Our selector tool helps you to find the most relevant journal

- We provide round the clock customer support

- Convenient online submission

- Thorough peer review

- Inclusion in PubMed and all major indexing services

- Maximum visibility for your research

Submit your manuscript at www.biomedcentral.com/submit
Biomed Central 